\title{
Fluid simulations in heritage science
}

\author{
Josep Grau-Bové ${ }^{*}$, Luca Mazzei², Matija Strlic ${ }^{1}$ and May Cassar ${ }^{1}$
}

\begin{abstract}
This review addresses the use of computational fluid dynamics for the interpretation and preservation of heritage. Fluid dynamic simulations in the heritage field focus mostly on slow air movement in indoor spaces and they usually involve temperature and humidity. Simulations have different roles: they may be exploratory, they may be used to support preventive conservation and occasionally they aid historical or archaeological interpretation. The research questions rarely involve testing or development of new mathematical formulations; instead, existing computational models are used as a means to help solve practical issues. Computationally, the simulations are typically steady-state and they always use a turbulence model. Experimental validations against measured data are uncommon and there is a need for the production of benchmarking cases and the publication of experimental data. Further research is needed in order to explore suitable approximations to the simulation of change in the time-scale of months or years, low turbulence flows for which current mainstream turbulence models are ill-suited, and new mathematical formulations for near-wall transport phenomena.
\end{abstract}

\section{Introduction}

Computational fluid dynamics (CFD) involves the calculation of fluid flows and their interaction with solids. Most historic materials are surrounded by a fluid, mostly air, in rare occasions water, sometimes a solid with a certain water content. It is widely acknowledged that air transports many of the agents of deterioration of concern for preventive conservation: heat, water in vapour phase, aerosols, spores and gaseous pollutants, as listed by Michalski [1]. Light, whilst aiding chemical reactions, also has heat generation as a by-product. Undoubtedly, the interaction of materials with agents of change does not only involve chemical reaction, but also some form of transport phenomena of matter and energy, between the fluid and the material it surrounds. In some instances the fluid motion is laminar, such as an air plume over a hot surface, in others turbulent, such as drafts in a historic house. All these processes can be described by CFD.

For the reasons above, computational fluid dynamics has been used for many years to interpret fluid motion in heritage contexts. Here we understand fluid dynamics as the scientific discipline that studies flows. The adjective

\footnotetext{
*Correspondence: josep.grau.bove@ucl.ac.uk

${ }^{1}$ Institute for Sustainable Heritage, University College London, London, UK

Full list of author information is available at the end of the article
}

"computational" refers to the methods of solving the equations that describe fluid motion in complex systems (i.e. too complex to be solved without a computer). This review uses some technical concepts that are specific to CFD. For an overview of the foundations of fluid dynamics, readers may refer to the classic textbook by Batchelor [2]. The development of this discipline is linked to the evolution of computation capacity and therefore it became widespread with the advent of affordable computers [3]. It was first applied to buildings and then to historic buildings, with some delay: The oldest paper cited in this review dates back to 1999 [4].

The use of CFD in historic buildings is preceded by the use of building energy simulations. Its application in ordinary buildings as well as those in the cultural heritage sector was reported at a Building Environmental Performance Analysis Club Seminar, RIBA London on 9 June 1994 by May Cassar in "Design Criteria for the Museums and Galleries Environment". This report identified the challenges and opportunities of simulation and described building projects that included simulations of energy and moisture transfer that were realised for organisations including Tate Gallery, St Ives; Tate Modern; Lady Lever Art Gallery, Liverpool; the Gas Hall, Birmingham, amongst others. The design advice included new totally passive museum buildings as well as the refurbishment of many existing museum 
buildings with conventional HVAC (Heating, Ventilation, and Air Conditioning) systems that were seeking to evaluate environmental performance options. Since then, the number of publications and applications has been rising steadily, as shown in Fig. 1, which shows the number of articles identified in this review. The scope of the research has diversified, expanding beyond buildings to cover all kinds of fluid motion in and around heritage spaces.

Even though fluid dynamics has been used notably in the field of heritage, there has not been until now any attempt to review the existing research. There have not been, in fact, any events, conferences or other academic initiatives that could act as fora for the definition of a shared research agenda. It seems, at a first glance, that the research efforts in this field have occurred in relative isolation. This review attempts to define this knowledge gap. We review the most significant research in fluid dynamics applied to heritage environments and materials, studying issues of model creation, set up and experimental validation. The purpose of the paper is to identify common themes, problems and research needs. The reviewed work has been published in varied outputs, ranging from conservation to engineering journals and including several conference papers. Of all the published papers that involve fluid dynamics and heritage (about 110), approximately half have been discarded for several reasons, the main one being a weak focus on heritage issues.

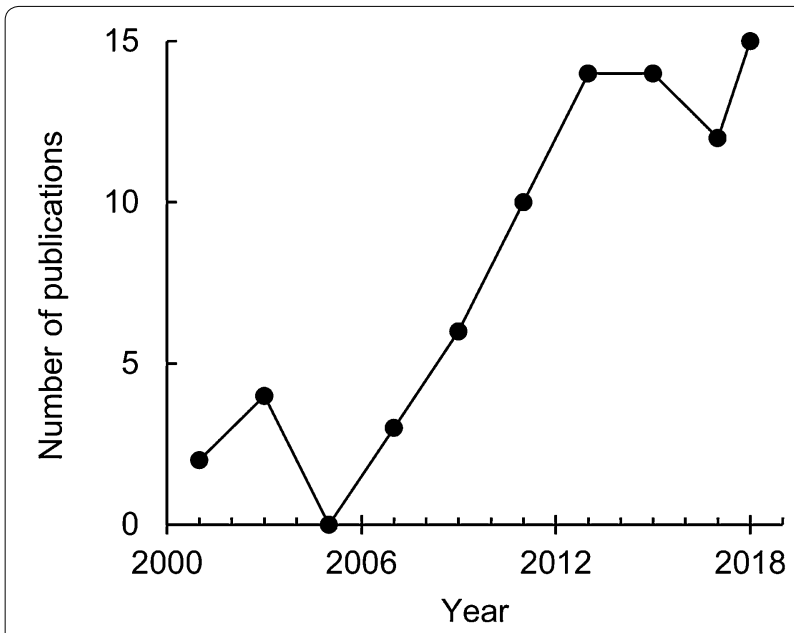

Fig. 1 Number of articles per year, counting only the publications identified in this review using the key words "CFD" and "Fluid Dynamics," "Heritage", "Museums" and "Archaeology" in Google Scholar, Scopus and Science Direct. Most of the publications counted are cited in the review

\section{Uses of fluid dynamics}

The subject of the majority of papers that describe fluid dynamic simulations in heritage is air motion (90\% of the 60 or so papers reviewed in this article), most of which indoors (70\%) and the rest outdoors (30\%). The remaining papers deal with a diversity of topics, such as water movement in ancient hydrological structures $[5,6]$.

The intent of CFD simulations in heritage is diverse. We have identified three loose categories of simulations according to their purpose. Firstly, we find the simulations that aim at obtaining a visualisation of air flow in an environment. Secondly, there are simulations that provide evidence for the historical interpretation of a site. Finally, there are simulations intended as an integral step of a design process, a conservation project or, more generally, that support decision-making. As we shall see, in all of these three categories we can find significant technological innovation, even though advancing the state of the art in fluid dynamics is rarely the main research objective of the reviewed articles. This was also a feature of the early building simulations of the 1990s which were undertaken in response to specific design questions and which were preceded by RH (Relative Humidity) and temperature monitoring campaigns.

\section{Type 1: Air flow visualisation}

As a general rule, obtaining the air flow pattern is the main objective of simulations of this type. Conservation implications are not necessarily part of the research. The simulations may be a tool to generate a hypothesis. They are motivated by very open research questions. For example, Balocco et al. [7] determined numerically the spatial distributions of temperature and humidity in the Salone dei Duecento of the Palazzo Vecchio (Florence, Italy). This research provides an understanding of two concepts (1) the dynamic behaviour of the environment and (2) a practical demonstration that this behaviour can be reproduced with simulations. These two are typical outputs of a large group of simulations.

The analysis of wind over the Giza plateau [8], a very different geometry, has similar outcomes: it produces a simulation at an scale unprecedented in a heritage setting and concludes that CFD is a useful tool for similar problems. The simulations of Corbusier houses by RaquenaRuiz [9] also have the main purpose of understanding the role of aérateurs (ventilation holes) in the regulation of the environment, without further conservation or design objectives. Often, such exploratory simulations result in interesting insights on the dynamics of a historic environment. An interesting example is the simulation of 
a shipwreck site by Smyth and Quinn [10], who explain how the presence of the ship alters flow patterns.

Many more examples can be cited: the simulation of natural ventilation in a historic house in Palermo [11], the simulation of air movement in a church and an art gallery in Prague (Czech Republic) [12], wind over a historic Chinese settlement [13], ventilation in vernacular Vietnamese structures [14], or dust in the historic centre of the city of Najaf (Iraq) [15]. In all these cases, the visualisation of the flow is the main output. An outstanding example of an exploratory simulation is the research on the effect of ventilation and occupancy in the historic Palatina Library (Parma, Italy) [16]. As shown in Fig. 2a, this simulation illustrates environmental dynamics that would be difficult to observe using experimental approaches.

This category of studies identify or display the main environmental processes, demonstrate the use of CFD and offer evidence for further interpretation. Their main purpose is to produce a computational reconstruction of the fluid motion alone i.e. without comparative physical measurements of that environment.

\section{Type 2: Simulations as historical evidence}

This category uses the simulations as evidence to aid the interpretation of a site. The hypothesis or research questions are historical or interpretative and the simulation is used as additional evidence. The simulation of a 10th Century Spanish waterwheel [6] is not only a good example of this category but also one of the few instances where the simulated fluid is water instead than air. The authors use simulations of the interaction between the river and the wheel to estimate the range of operating velocities $(0.91$ to $1.01 \mathrm{~m} / \mathrm{s})$ and the flow levels required for a successful operation, as shown in the contours of velocity around the wheel in Fig. 2c. They conclude that the waterwheel would be operative for 124 days a year, with an additional 74 days if dams were used to regulate the channel. In a similar vein, the study of a historic watermill in Besalú (Catalonia) provides an estimation of its energy efficiency [5] which improves previous assumptions based on historical sources.

Simulations of water flows have also been successfully used to validate hypothesis on the principle of operation of ancient hydrological designs. For example, simulations of a water pipeline in Petra (Jordan) have show that its designers had advanced knowledge of fluid dynamics [17]. The inclination of the pipes is sufficient to promote the flow of water, but low enough to avoid pressure losses due to turbulence. Similar water supply systems have been simulated in Apamea (Syria) [18] and in the case of Minoan terracotta pipes [19].

There are instances where ancient structures were created to induce certain air flow patterns. The simulation of warehouses in the ancient Roman ports of Portus and Ostia (Italy) is another case of historical evidence obtained through fluid simulations [20]. In this collaborative research, archaeologists provided different possible interpretations of the layout of the ancient warehouses based on the existing remains. The authors simulated the
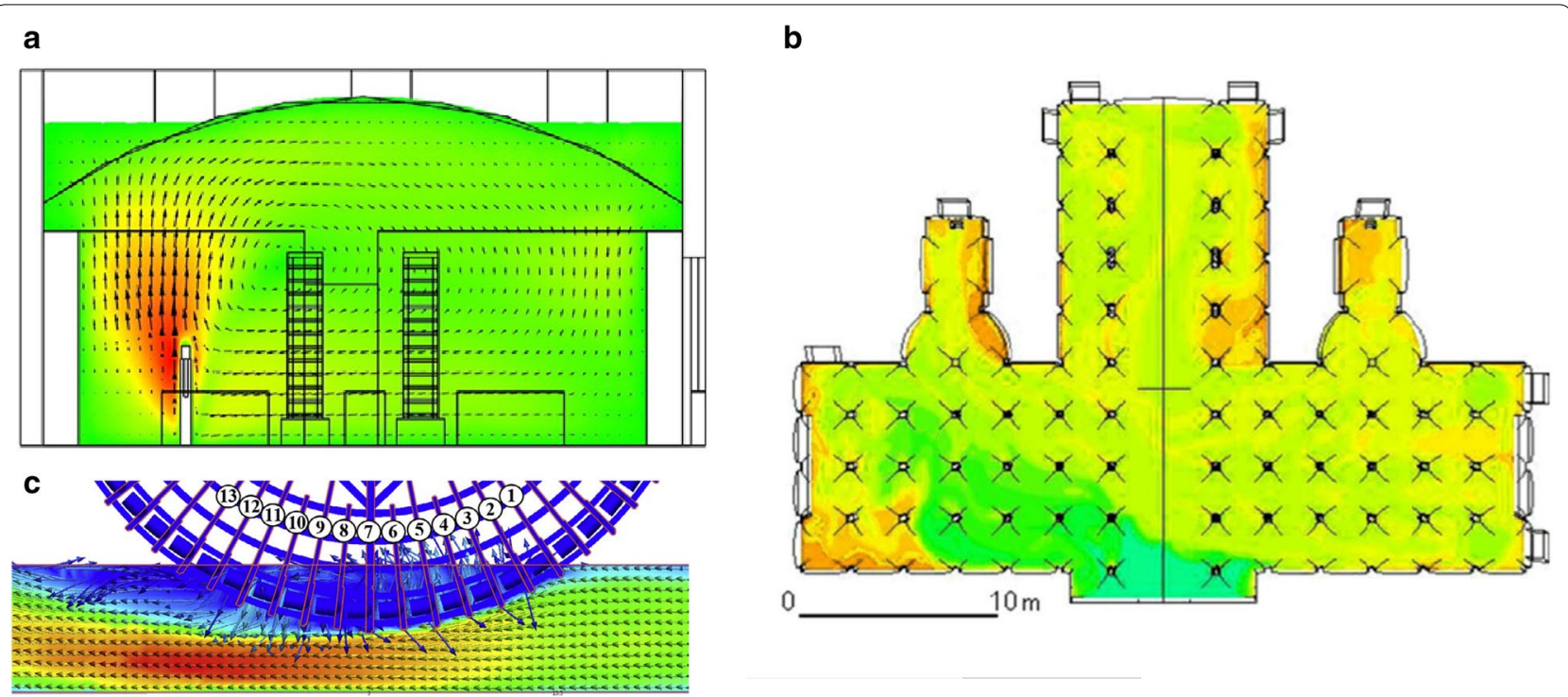

Fig. 2 The different uses of CFD. a The contours of velocity and temperature used to understand the behaviour of the environment in connection to occupancy in a library [16], b shows the distribution of humidity used to aid decision making in a preventive conservation context [26] and c shows the profile of water velocity used to aid the historical interpretation of an ancient waterwheel [6] 
hypothetical designs in order to investigate which options were more suitable for food storage. The CFD simulations demonstrate conclusively that only the designs that include ventilation outlets in certain locations were likely to achieve appropriate storage conditions in the summer months, when the warehouses were in use. Huang et al. [21] simulate iron smelting furnaces in order to interpret the historical evolution of their design. Their research reveals the role of some design features, which improved air circulation. A Sri Lankan furnace is simulated by Tabor [22]. Similarly, a study of the Pitti Palace in Florence validates with simulations an hypothesis of the operation of the original ventilation system [23]. A CFD study of the Tjibaou Cultural Center (New Caledonia), rather than exploring a historical question, evaluates whether the intent of the architects is satisfied by the aerodynamic performance of the final design [24].

\section{Type 3: Simulations for preventive conservation}

Finally, we find simulations that are used to support decision-making processes. These processes may consist of the design of ventilation systems, building layouts or urban plans and in some instances preventive conservation plans. Often, CFD is needed in order to explore design alternatives in systems that offer little flexibility for environmental control. A seminal example that sets the capabilities of the technology is the use of CFD in combination with monitoring and other simulation techniques to explore heating strategies for churches in the project Friendly Heating [25].

One of the projects that can be considered as an exemplary use of fluid dynamic as a preventive conservation tool is the simulation of moisture dynamics in the crypt of the Lecce Cathedral (Italy) [26]. This study involves the simulation of air motion and moisture transport (including evaporation from walls) in a large, naturally ventilated space. An example of the moisture maps produced in this research can be found in Fig. 2c. Several features make this work stand out. Firstly, air velocity is experimentally validated-a key step which is further discussed in the following sections. Secondly, the simulations successfully inform the preventive conservation strategy with evidence that would have been difficult to obtain solely with experimental methods. Specifically, the simulations indicate which windows have a dominant effect on the presence of moisture in areas where it should be avoided and therefore can be used to choose those windows that should remain closed or be sealed. Fluid dynamics also plays a key role in the investigation of suitable ventilation strategies for the conservation of St. Martin church in Oberesslingen (Germany) [27]. This research aims at avoiding temperature gradients in the air volume surrounding the pipes of a historic organ. It is based on a sound discussion of the ideal thermal conditions for the conservation of pipe organs.

The analysis of hypothetical scenarios is one of the main ways in which CFD can be used in conservation. For example, it has been used to simulate aerosol deposition in indoor heritage under different scenarios of wind direction, and under different ventilation strategies [28]. Pineda and Iranzo [29] have simulated how several preservation strategies can reduce the erosion of stone columns. Their simulations include hypothetical future scenarios where protective walls are installed around a site. CFD has also has been used to investigate different directions of ventilation outlets in the Palazzo Madama (Turin, Italy) [30] in order to obtain good air mixing and stable temperatures. Occasionally, simulations are used as an investigative tool to find the causes of ongoing or existing damage in historic materials. In a study of drifting sand particles in the Mogao Caves (Dunhuang, China), the simulated near-wall air velocity was found to correlate well with the observed spatial distribution of deterioration [31].

The three types of simulations of heritage environments identified in this section (As air-flow visualisation, as historical evidence, and for preventive conservation) share an interest in obtaining practical solutions. It is rare that simulations are carried out for purely developmental reasons, such as creating a new computational model for a specific conservation problem. Instead, research is almost exclusively driven by case studies and practical issues.

\section{Relationship of the models with reality}

The processes of change of interest in heritage environments take place generally over decades or years rather than hours or seconds [32]. Short term processes such as humidity or temperature fluctuations are usually a concern because of their long-term effects. The emphasis on long-term material change and the cumulative effects of rapid variations could be seen to be at odds with the nature of CFD, which is best suited for the simulation of short time-spans or steady state problems. There are, however, many ways to represent reality with CFD. The key is the choice of the time span represented by the simulations.

\section{Time representation}

There are fundamentally three ways of representing time in CFD, each with several variants. Some examples are shown in Table 1, which is discussed in the following section. Firstly, the simulation can represent an unchanging state that is true for a certain period that could be infinitely long, which is known as steady state. Secondly, we find pseudo-transient simulations, which represent a 
Table 1 Summary of experimental validations and definitions of the representativeness of simulations

\begin{tabular}{llllll}
\hline Site & Type & Time or scenario & Quantity & Description & Refs. \\
\hline Crypt & SS & Winter and summer & T, RH, & Spatially resolved, averaged for season & [26, 44] \\
Large outdoors site & SS & Prevailing winds & $\mathrm{V}$ & Pre-validated with literature data & [8] \\
Exhibition space & SS & Ventilation scenarios & $\mathrm{T}$ & Spatially resolved & [43] \\
Window frame & $\mathrm{SS}$ & Different designs & & Spatially resolved & Single point, seasonal averages \\
Chapel & $\mathrm{SS}$ & Winter and summer & $\mathrm{T}$ & Several points, continuous data \\
Church & Trans & $5 \mathrm{~h}$ & $\mathrm{~T}$ & Single point, continuous data & [33] \\
Library & Trans & $12 \mathrm{~h}$ & $\mathrm{~T}, \mathrm{RH}$ & {$[45]$} \\
\hline
\end{tabular}

The column type indicates whether a simulation is steady state (SS) or transient (Trans). The column time or scenario shows the criteria used to define each simulation, which is either a timespan or certain steady-state situation. The column Quantity indicates the parameter measured in the validation experiments ( $\mathrm{T}$ is temperature, $\mathrm{RH}$ is the relative humidity, $\mathrm{V}$ is air velocity)

series of steady state scenarios that approximate a continuous variation, for example, winter and summer conditions or monthly conditions. In other words, time steps that are significantly longer than the time that the system takes to reach steady-state conditions. Finally, there are transient simulations, which aim to resolve the equations for every time step of the evolution of the system.

All these methods have been used in the simulation of heritage environments. When the simulations involve the design of a ventilation system, or the layout of a site, it is usual to use steady state simulations that represent the typical operating scenarios. Some simulations divide the year in two seasons [4, 30,33], some in three, such as winter, summer and intermediate seasons [34] and some use constant conditions during single months [35]. Steady state simulations usually represent any time period where boundary conditions can be considered constant. They may also represent design scenarios that are not associated with any time-span. For example, different combinations of open or closed windows [36], different wind directions [8] or different positions of the ventilation inlets [27].

Finally, we find transient simulations that approximate the evolution of a system. These simulations by nature must represent shorter time-spans, such as the evolution of indoor temperature distributions during a few hours [37], half a day [38, 39] or a day [7]. A day is the longest time identified in this review for a transient simulation. On the one hand, transient simulations have the disadvantage of representing only a short period of time, which may limit the interpretation of the results. On the other hand, their main advantage is that the results can be easily compared with experiments, because it is generally easy to monitor during the simulated period. The transient simulation of air movement and moisture in the Palatina library (Parma, Italy) $[38,40]$ is an example of a successful validation with representative results. In this case, the transient simulations are validated using a $12 \mathrm{~h}$ dataset of temperature. Afterwards, the model is used to simulate several scenarios of ventilation and heating [16].

\section{Experimental validation}

Only a quarter of the published simulations are experimentally validated. This is lower than other instances of the use of CFD. For example, a random sample of 50 CFD papers published in Building and Environment from 2010, reveals that $78 \%$ of the CFD simulations are experimentally validated. Most experimental validations in the heritage field consist of a pre-validation, i.e. a validation with similar data collected in the site of interest or elsewhere, which is used to gain confidence in the model before applying it to other scenarios. For example, one can validate a model in a small-scale lab experiment before simulating more complex geometries [41]. Validation is closely linked to the time representativeness of the simulations, because the data available for comparison often defines the length of time that simulations need to cover and vice versa. For this reason, some examples of both are summarised in Table 1 . Validation can be carried out with any of the parameters predicted by the models. The more parameters are used, the more aspects and equations of the model can be validated.

Temperature is the most common parameter used to compare simulations with reality. This is understandable: temperature is easy to measure in different locations simultaneously. It is also an indication of the thermal energy, which is a transported scalar in the computational models and as such, it can be used to validate the performance of the solution of the transport equations. Only two simulations are validated with measurements of velocity, which contrasts with the common practice in other fields. For example, in the simulation of wind in street canyons validations against velocity measurements are usual. Only three simulations are validated with spatially-resolved data. In a simulation of window frames [42] the measurements are of a vertical profile of 
temperature. Two building simulations are validated with measurements of temperature in different locations [43, 44]. In one instance, simulations of dust deposition have been compared with data of dust deposition in several rooms [28]. Comparisons with experimental data, common in other fields, are relatively rare in heritage.

\section{Physical systems}

Historic objects interact with many types of fluid motion, from moisture diffusion in a multi-layered painting to rain over a large outdoor sculpture. The reality is, however, that CFD simulations in the heritage context are concerned with a small subset of all the possible geometries and flow regimes. This section reviews the different physical systems that have been simulated using CFD.

\section{Geometry and space}

Rooms are the most usual subject of CFD studies in heritage. Figure 3 shows a histogram of the dimension of the computational domain used in the publications reviewed here. We calculate the size of the computational domain as the diagonal dimension (i.e. the distance between the two most distant vertexes), calculated as for two dimensional spaces and for three dimensional spaces, where $x$, $y$ and $z$ are the three dimensions of the smallest parallelepiped enveloping the whole geometry. The majority of the simulations $(77 \%)$ have a dimension between 1 and $100 \mathrm{~m}$, which corresponds to indoor spaces. The majority of these have a dimension between 10 and $50 \mathrm{~m}$ and they are halls, churches, exhibition spaces and galleries. Figure 4 shows some examples of the diversity of size-scales that have been simulated. These range from a metre to several kilometres.

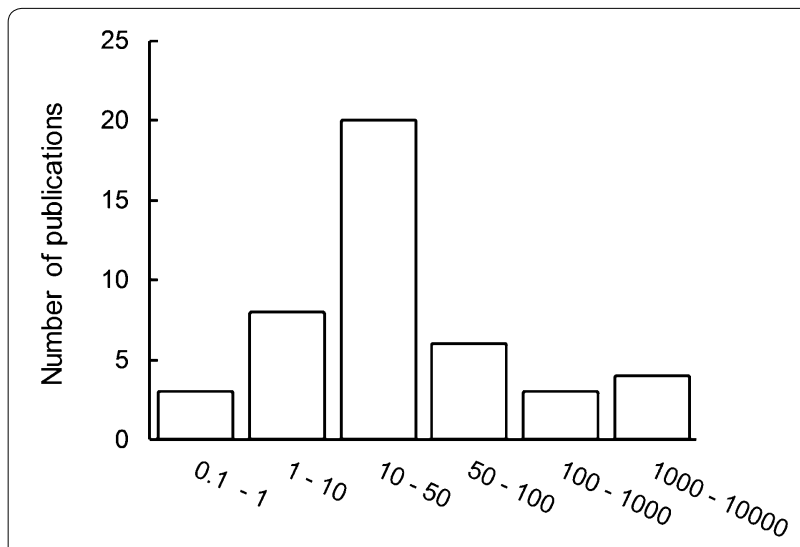

Diagonal dimension of computational grid $(\mathrm{m})$

Fig. 3 Histogram of model dimensions (taking the longest diagonal in the computational space), using the publications reviewed in this paper. Note that the width of the bins is not even, in order to show more clearly the distinctions in the 10-100 m range
It is relatively rare (less than $5 \%$ of cases) that spaces smaller than $1 \mathrm{~m}$ are simulated. The cases reported here correspond to a study of evaporation of rising damp in a wall section of a historic building [46], a simulation of a protective glass frame [37] and the erosion of a marble statue due to the impact of airborne particles [47]. There are no simulations of indoor micro-environments such as display cases, which have been successfully simulated in other areas of inquiry such as the case of refrigerated display cases for the food industry [48]. The performance of double-glazing is another small-scale process of interest to heritage that can be well described with CFD [49]. Another under-used application of CFD in heritage, is the simulation of the interaction between small objects and their surrounding environment. In the food industry, it is usual to use CFD to predict the drying rate of fruit [50]. These simulations could be directly translated to processes of water absorption in historic materials.

The largest heritage environments simulated with CFD range from hundreds of meters to several kilometres. This is the case of simulations of historic villages or city centres $[13,14,51,52]$ or large building complexes [8, 24]. These simulations are at the largest end of the spectrum of application of CFD. When working with geometries of several kilometres, the compromise between detail and computation time often implies that geometrical detail needs to be proportionally reduced. As a result, simulations larger than several kilometres are rare in the application of CFD in heritage sites.

In view of the evidence, it can be said that in heritage science CFD is predominantly being used as a tool for the simulation of indoor phenomena, with a few notable exceptions.

\section{Field variables of interest}

We have already seen that the vast majority of simulations involve air motion, with the exception of a few investigations of water flows [5]. In many instances, however, air is the carrier of other scalar quantities of interest. Less than a quarter of the reviewed papers is concerned exclusively with air motion. It is usual to simulate the distribution of temperature. The other most simulated parameter (26\% of the publications) is relative humidity. Only a minority of articles involve a simulation of other scalars, such as particulate matter [38] or gaseous pollutants. These observations are summarised in Fig. 5. The interaction between surfaces and pollutants is absent in heritage publications, while it has been successfully simulated in other fields. For example, CFD has been used to simulate the emissions of volatiles from building materials [53]. This approach would have clear uses in heritage spaces such as storage of plastics, where emission and deposition of volatiles can be of interest. 


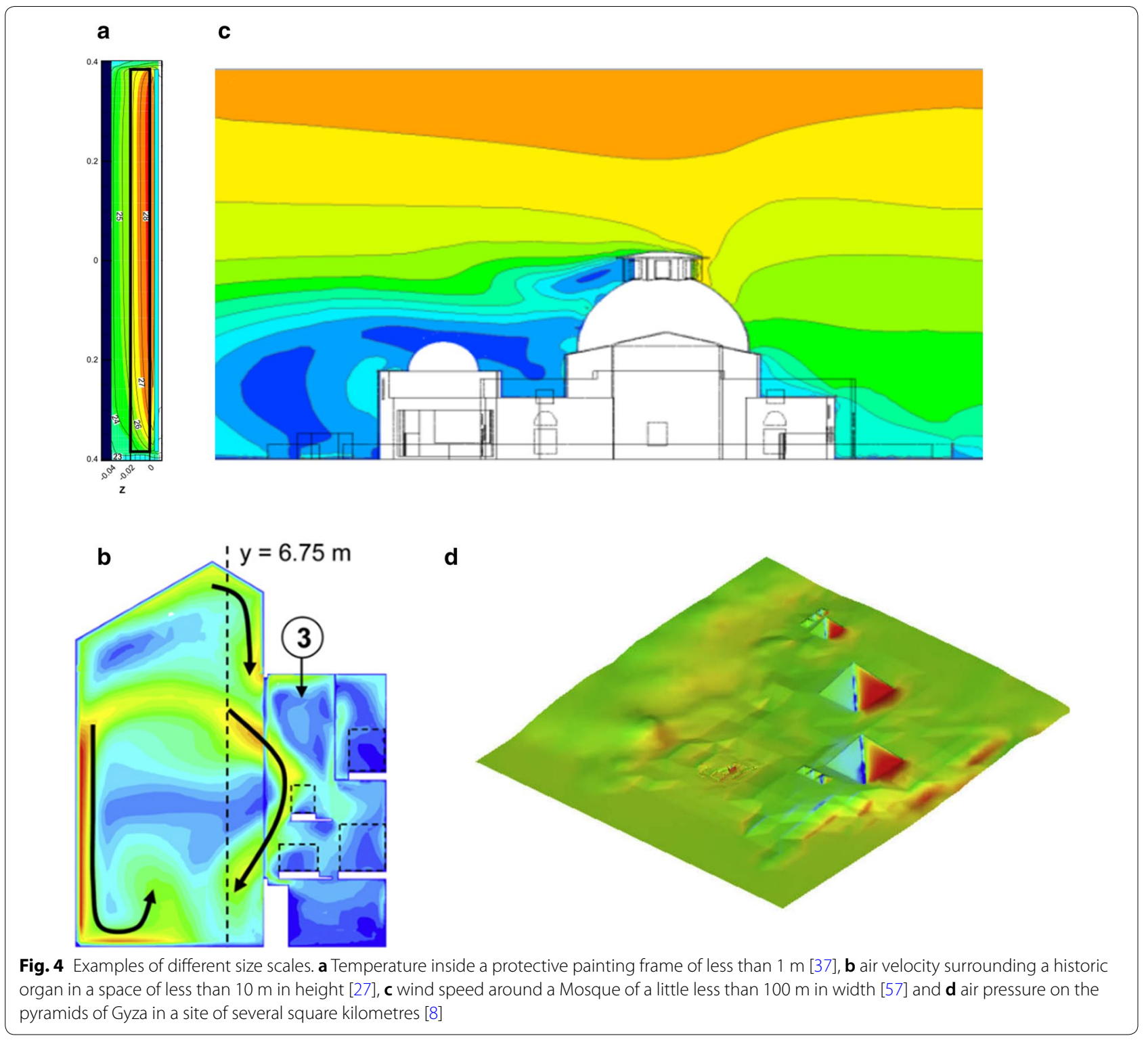

The predominance of simulations of temperature and humidity may be explained by the predominant role of these parameters in many processes that affect heritage materials. Temperature has been simulated as a concern for materials, such a church organ preservation [27], but also for human comfort [9]. Temperature is the key parameter in the design of sustainable heating strategies that minimise energy consumption while obtaining appropriate conditions, for objects and for occupants $[43,54]$. The simulations of temperature often aim at obtaining a homogeneous environment (i.e. without sharp gradients), as in the work by Corgnati [30]. All the reviewed simulations of humidity focus on its transport through air, but not on transport towards or from walls (condensation, absorption or evaporation). The assumption that these transport phenomena are negligible is not usually justified, even though it can be understood from the context that they would not change the results significantly. One of the few examples of a CFD simulation of moisture transport through heritage materials is the simulation of the hydrothermal behaviour of a protective glass frame for paintings [37]. This work reports a model for the transport of moisture in air and within the porous elements of the frame. The model is experimentally validated in laboratory conditions before being used to simulate the frame of interest.

The general lack of transported quantities other than temperature in the literature may be due to the 


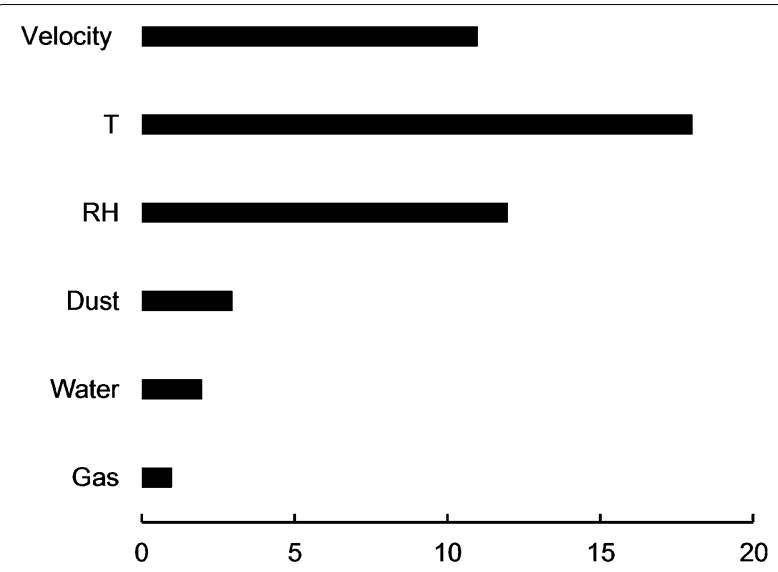

Fig. 5 Number of reviewed publications that simulate different agents of deterioration. The bars show the number of publications that have as a main focus each field variable. It should be noted that velocity is not a field variable, instead it indicates the simulations that do not include any other field variable other than momentum. $T$ indicates the simulation of thermal energy. Naturally, $\mathrm{RH}$ simulations also require thermal energy

complexity of the models. Temperature, humidity (if it does not interact with surfaces) and gases (if they do not deposit) can be simulated with well-established equations for scalar transport, which are provided by default in many commercial codes (see, for example, [55]). In order to simulate phenomena that involve some type of surface interaction (e.g. deposition, condensation, evaporation, adsorption or emission), the models need to be extended with estimations of boundary conditions or improved transport equations, which often require further research that falls outside the scope of many of the CFD studies of heritage environments.

\section{Predicted velocities and their origin}

The estimation of fluid movement is the main role of CFD models. The choice of mathematical models depends on the type of fluid motion. Diffusive or convective systems, high or low turbulence systems, should be simulated using different approaches.

The velocities of interest in indoor heritage spaces, draughts excluded, are low, below $0.5 \mathrm{~m} / \mathrm{s}$. Figure 6 shows the velocity ranges of the CFD output of all the articles reviewed (for simplicity, references are not provided in the Figure). There are several general issues to consider. Firstly, the simulated velocities are usually too low for the sensitivity of common air velocity sensors. For example, a contemporary high sensitivity hot-plate sensor would be able to measure a minimum velocity of $0.1 \mathrm{~m} / \mathrm{s}$ with an accuracy of $3.8 \%$ [56]. However, $30 \%$ of the reviewed simulations report values under this limit. This indicates a great difficulty of experimental

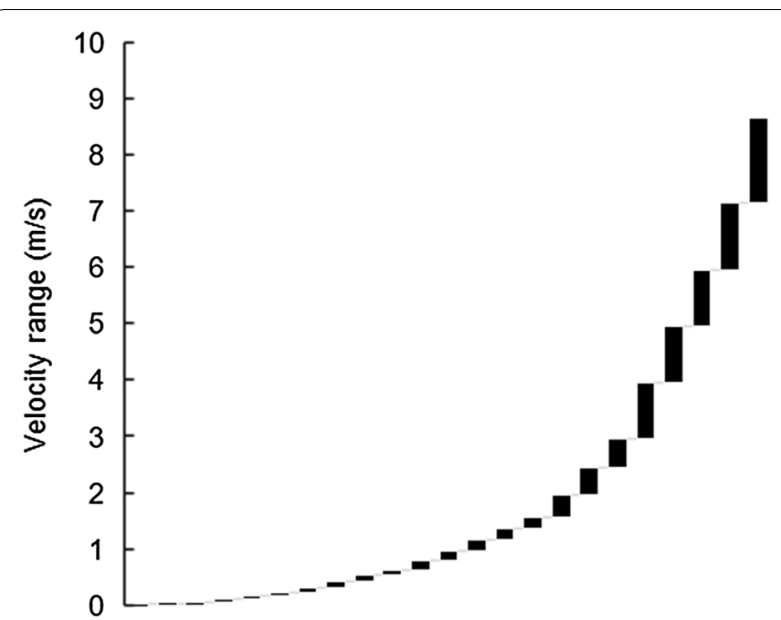

Fig. 6 Velocity ranges of the simulation outputs in all reviewed articles, ordered from low to high. The vertical bars begin at the lowest velocity reported and end at the highest one

validation. It may be one of the reasons why only two of the reviewed papers validate the simulations using measurements of air velocity.

Secondly, the CFD simulation of air flow motion requires the use of different models for laminar and turbulent flows. Given the low velocities indoors, some flows are usually below or very close to the threshold of turbulence. It should be highlighted that low turbulence is actually more problematic than high turbulence. The majority of turbulence models, and certainly all the models available in commercial codes, are prepared for very high turbulence levels. It is unclear how applicable these models are to the potentially low turbulence levels found in historic buildings, and yet these are the models that are commonly used. Using turbulence models when the flow is not turbulent can result in overestimations in the transport of heat and mass. Only the simulation of a protective painting frame by Steeman [37], which leads to very small velocities (the geometry can be seen in Fig. 3a), acknowledges that the flow field is laminar.

\section{Sources of high velocity flows}

The highest velocities, as expected, appear when wind plays an important role. For example, the study of wind around a minaret (Konya, Turkey) [57] in relation to its capacity to cool or heat its thermal mass, finds velocities between 0.4 and $1.6 \mathrm{~m} / \mathrm{s}$. The analysis of ventilation patterns in vernacular courtyards in la Havana (Cuba) finds velocities between 0.5 and $3 \mathrm{~m} / \mathrm{s}$ [58] and the study of wind-driven particle collisions on the wall paintings of the Mogao Caves (Dunhuang, China), finds velocities between 0.2 and $1.5 \mathrm{~m} / \mathrm{s}$ [31]. 


\section{Sources of low velocity flows}

Lower velocities have more diverse causes. A common source are temperature differences. The study of the Palatina Library (Parma, Italy), is an example of air motion generated by the presence of visitors [38]. In this case visitors are considered as an immobile source of thermal energy, which creates a vertical plume rise. In fact, introducing humans as static thermal sources is not an uncommon approach. In the field of building physics, occupants have been simulated in CFD either as simple cuboid geometries [59] and more recently with realistic human shapes [60]. One of the first applications of CFD to model a heritage space is the simulation of the Archaeological Museum of Athens [4], where visitors were accounted for as a source of heat.

The inclusion of visitor movement is a very recent development [16] and its simulation and interpretation may still require further research. Specifically, the air motion caused by visitor motion needs to be experimentally determined. Models should also be able to reflect the variability in visitor behaviour. Another common source are ventilation inlets, which display initial high turbulence which reduces as the air moves away from the source. One example is the study of ventilation in a historic hall of the university of Wroclaw (Poland), where air inlets are located underneath the seats [61]. In this case the inlet velocity is $0.5 \mathrm{~m} / \mathrm{s}$ and reduces to under $0.05 \mathrm{~m} / \mathrm{s}$ in the areas further away from the air sources. The simulation of a design of ventilation around a church organ shows a similar decay of velocity, from $3 \mathrm{~m} / \mathrm{s}$ at the input to a few centimetres per second in the spaces between the organ pipes [27]. This is a common feature of air motion indoors: after leaving the ventilation output, the air velocity decays by at least one order of magnitude, sometimes two, in a few meters, as seen in many of the reviewed articles $[33,62,63]$.

\section{A notorious absence: turbulence and boundary conditions}

When setting up a CFD simulation, the user has to make several choices regarding the mathematical equations that need to be solved. Some of the most important choices are: what type of turbulence model is used, how is the transport of other quantities (energy, pollutants, moisture) implemented and how does the model describe the interaction of these quantities with surfaces. The latter is a very notorious absence in the reviewed papers. It can be argued that the interaction between objects and environment is precisely the main interest of heritage scientists. However, the equations that describe this nearwall phenomena are never explicitly discussed.
Even though we have found a great variety of types of fluid motion, all of them are simulated with the same model. All the studied examples use the $k-\varepsilon$ turbulent model, with very few exceptions: the simulation of a watermill uses $k-\omega[5]$ and a simulation of air conditioning in a museum uses a zero-equation model [64]. Only one article compares the performance of different turbulence models [27]. The predominance of the $k-\varepsilon$ model may be explained because of the suitability of this model for the simulation of air flow in rooms. This model is frequently used for simulations of the built environment [65] and has been shown to produce acceptable results for low turbulence when it is combined with dampening functions [66]. However, the reviewed literature generally reports the use of the $k-\varepsilon$ model with little or no justification.

The most used code to solve these equations is ANSYS Fluent, in approximately half of the papers, while the other half uses a great diversity of codes: Phoenics, Pardiso, Comsol, Star-CD, OpenFOAM, CFX or Design Builder. The predominance of Fluent is constant over the years. All these codes have similar core capabilities (they can solve fluid flow equations in laminar and turbulent conditions). Many of them, including OpenFoam, CFX and Fluent, are highly customizable with user-defined equations. However, most of the reviewed papers do not use this functionality.

\section{Conclusions}

The simulation of fluid motion in heritage is predominantly concerned with air motion, particularly indoors. We have observed that there are great similarities between the many published simulations: geometries tend to have a size between 10 and $50 \mathrm{~m}$, the simulated fluid is typically air, mainly transporting thermal energy and humidity. The air motion is usually simulated as turbulent and $k-\varepsilon$ is the model of choice to simulate turbulence. The research questions can be classified in defined groups: historical interpretation, exploration of the dynamics of an environment, and improvement of environmental design for preventive conservation.

And yet, despite this apparent homogeneity of objectives and methods, it seems unfitting to speak of this body of work as a well-defined scientific discipline. The reason may be that even if each publication is well aware of its scientific framework, they are not necessarily aware of each other. In other words, the simulations of heritage spaces emerge individually to resolve specific issues, but they do not share research questions or coordinate research efforts. However, many shared issues exist and they should become the basis of future investigations. In the view of the authors, the following research issues arise from the observations in this review: 
- The time-scale problem There is a miss-match between the time-scales that are usually simulated (from hours to months) and the long-term nature of processes of change. Simply put, hourly variations that cause damage over years cannot be realistically simulated with the existing CFD technology. Researchers approach this issue in many ways: using representative conditions for long periods of time, or simulating change during a few hours. However, research is needed to find the appropriate time-scale for the variety of issues of interest for heritage science.

- The need for validation There is a need for more comparisons between simulations and real world data, collected in the simulated environment. The difficulties of this task in heritage environments are many: slow change, difficulty of monitoring, the uniqueness of the sites studied and their conditions. But there is scope for further research on the validation of CFD models. Firstly, since CFD aims at simulating the spatial distribution of a quantity, validations should also use spatially distributed data. Secondly, there is a need for the development of benchmark cases that can be used for the validation of models of a diversity of conservation issues, to be used when other types of validation are not possible.

- The low-turbulence problem Velocities indoors are usually low (under $0.1 \mathrm{~m} / \mathrm{s}$ ) and sometimes air flows may not be fully turbulent. Even though the $k-\varepsilon$ model seems to provide acceptable results, there needs to be a critical reflection on the use of turbulence models in indoor heritage spaces. Further research is needed in the assessment of the levels of turbulence found indoors and the methods to model it.

- The near-wall problem In the authors' experience, the interest of heritage managers is not only on the value of transported quantities in the centre of rooms, but particularly on the value close to valuable surfaces. Despite the emphasis on the interaction between air and heritage materials, few published simulations include estimations of wall fluxes, such as evaporation or condensation of moisture or dust and gas deposition. This may be a valid assumption in many instances, but in any case it should be explicitly discussed. The implementation of such models will, additionally, require computational refinements close to surfaces that may differentiate heritage CFD models from other indoor simulations.

\section{Towards best practice guidelines for heritage simulation} The quantity and quality of publications in this field has been increasing steadily during the last decade. There are several publications that set an example of the possibilities of CFD in heritage science. There is scope to develop guidelines on what should be considered best practice in the simulation of flows in heritage. Best practice guidelines exist for many CFD applications, for example, there are well-known guidelines for the simulation of flows in the urban environment [67] and indoor flows [68]. Future research should aim at establishing similar guidelines for CFD simulations in heritage contexts. As a first approximation, we have observed exemplary uses of CFD in heritage to fulfil the following criteria:(1) the simulations are experimentally validated, if possible in the environment of interest and if possible using spatially resolved data, (2) the authors critically assess the suitability of the boundary conditions, turbulence models and assumptions on the interaction with surfaces, (3) the authors report and assess the time-scale of the problem and its relationship with the real world and finally (4) the authors use conservation criteria in order to analyse the results and the usefulness of the model. Given the difficulties for experimental validation, it would be desirable that future publications report the experimental data in sufficient detail, in order to allow others to use the data for validation.

\section{Authors' contributions}

JG-B has compiled the papers and produced the final manuscript, MC, MS and LM have contributed to interpretation and written several sections. All authors read and approved the final manuscript.

\section{Author details}

${ }^{1}$ Institute for Sustainable Heritage, University College London, London, UK. ${ }^{2}$ Department of Chemical Engineering, University College London, London, UK.

\section{Acknowledgements}

Not applicable.

\section{Competing interests}

The authors declare that they have no competing interests.

Availability of data and materials

Not applicable.

Funding

No funding sources to report.

\section{Publisher's Note}

Springer Nature remains neutral with regard to jurisdictional claims in published maps and institutional affiliations.

Received: 25 July 2018 Accepted: 6 March 2019

Published online: 13 March 2019

\section{References}

1. Michalski S. A systematic approach to preservation: description and integration with other museum activities. Stud Conserv. 1994;39(sup2):8-11. 
2. Batchelor CK, Batchelor G. An introduction to fluid dynamics. Cambridge: Cambridge University Press; 1967.

3. Wendt J. Computational fluid dynamics: an introduction. A von Karman Institute book. Berlin: Springer; 2008.

4. Papakonstantinou KA, Kiranoudis CT, Markatos NC. Computational analysis of thermal comfort: the case of the archaeological museum of Athens. Appl Math Model. 2000;24(7):477-94.

5. Pujol T, Solà J, Montoro L, Pelegrí M. Hydraulic performance of an ancient Spanish watermill. Renewable Energy. 2010:35(2):387-96.

6. Castro-García M, Rojas-Sola JI, de Morena-de la Fuente E. Technical and functional analysis of Albolafia waterwheel (Cordoba, Spain): 3D modeling, computational-fluid dynamics simulation and finite-element analysis. Energy Conv Manag. 2015;92:207-14.

7. Balocco C. Daily natural heat convection in a historical hall. J Cult Herit. 2007:8(4):370-6.

8. Hussein AS, El-Shishiny H. Influences of wind flow over heritage sites: a case study of the wind environment over the Giza Plateau in Egypt. Environ Model Softw. 2009;24(3):389-410.

9. Requena-Ruiz I. Thermal comfort in twentieth-century architectural heritage: two houses of Le Corbusier and André Wogenscky. Front Archit Res. 2016;5(2):157-70.

10. Smyth TAG, Quinn R. The role of computational fluid dynamics in understanding shipwreck site formation processes. J Archaeol Sci. 2014;45:2205. https://doi.org/10.1016/j.jas.2014.02.025.

11. Balocco C, Grazzini G. Numerical simulation of ancient natural ventilation systems of historical buildings. A case study in Palermo. J Cult Herit. 2009:10(2):313-8.

12. Barták M, Drkal F, Hensen J, Lain M, Matuska T, Schwarzer J, et al. Simulation to support sustainable HVAC design for two historical buildings in Prague. In: Proc. 18th conference on passive and low energy architecture, PLEA; 2001. p. 903-8.

13. Tang L, Nikolopoulou M, Zhao F, Zhang N. CFD modeling of built air environment in historic settlements: village microclimate. In: 2011 international conference on computer distributed control and intelligent environmental monitoring; 2011. p. 1086-92.

14. Nguyen AT, Tran QB, Tran DQ, Reiter S. An investigation on climate responsive design strategies of vernacular housing in Vietnam. Build Environ. 2011:46(10):2088-106.

15. Al-Baghdadi MAS. CFD modeling of dust dispersion through Najaf historic city centre. Int J Energy Environ. 2014;5(6):723-9.

16. Balocco C, Petrone G, Cammarata G. Numerical multi-physical approach for the assessment of coupled heat and moisture transfer combined with people movements in historical buildings. Build Simul. 2014;7(3):289-303.

17. Ortloff CR. Water engineering at Petra (Jordan): recreating the decision process underlying hydraulic engineering of the Wadi Mataha pipeline system. J Archaeol Sci. 2014;44:91-7.

18. Haut B, Viviers D. Analysis of the water supply system of the city of Apamea, using computational fluid dynamics. Hydraulic system in the north-eastern area of the city, in the Byzantine period. J Archaeol Sci. 2007;34(3):415-27.

19. Tseropoulos G, Dimakopoulos Y, Tsamopoulos J, Lyberatos G. On the flow characteristics of the conical Minoan pipes used in water supply systems, via computational fluid dynamics simulations. J Archaeol Sci. 2013;40(4):2057-68.

20. Pagliaro F, Bukowiecki E, Gugliermetti F, Bisegna F. The architecture of warehouses: a multidisciplinary study on thermal performances of Portus' roman store buildings. J Cult Herit. 2015;16(4):560-6.

21. Huang X, Qian W, Wei W, Guo J, Liu N. 3D numerical simulation on the flow field of single tuyere blast furnaces: a case study of the Shuiquangou iron smelting site dated from the 9th to 13th century in China. J Archaeol Sci. 2015;63:44-58.

22. Tabor GR, Molinari D, Juleff G. Computational simulation of air flows through a Sri Lankan wind-driven furnace. J Archaeol Sci. 2005;32(5):753-66.

23. Balocco C. Analysis of ancient natural ventilation systems inside the pitti palace in florence. In: Proceedings of the COMSOL conference $2008 \mathrm{Han}$ nover; 2008.

24. Wu YC, Yang AS, Tseng LY, Liu CL. Myth of ecological architecture designs: comparison between design concept and computational analysis results of natural-ventilation for Tjibaou Cultural Center in New Caledonia. Energy Build. 2011;43(10):2788-97.
25. Camuffo D, Pagan E, Rissanen S, Łukasz B, Kozłowski R, Camuffo M, et al. An advanced church heating system favourable to artworks: a contribution to European standardisation. J Cult Herit. 2010;11(2):205-19.

26. D'Agostino D, Congedo PM. CFD modeling and moisture dynamics implications of ventilation scenarios in historical buildings. Build Environ. 2014;79:181-93.

27. Pitsch S, Holmberg S, Angster J. Ventilation system design for a church pipe organ using numerical simulation and on-site measurement. Build Environ. 2010;45(12):2629-43.

28. Grau-Bové J, Mazzei L, Malki-Ephstein L, Thickett D, Strlič M. Simulation of particulate matter ingress, dispersion and deposition in a historical building. J Cult Herit. 2016;18:199-208.

29. Pineda $P$, Iranzo A. Analysis of sand-loaded air flow erosion in heritage sites by computational fluid dynamics: method and damage prediction. $J$ Cult Herit. 2017;25:75-86.

30. Corgnati SP, Perino M. CFD application to optimise the ventilation strategy of Senate Room at Palazzo Madama in Turin (Italy). J Cult Herit. 2013;14(1):62-9.

31. Mikayama A, Hokoi S, Ogura D, Okada K, Su B. Effects of drifting sand particles on deterioration of mural paintings on the east wall of Cave 285 in Mogao Caves, Dunhuang. Energy Procedia. 2015;78:1311-6.

32. Dillon C, Lindsay W, Taylor J, Fouseki K, Bell N, Strlič M. Collections demography: stakeholders' views on the lifetime of collections. In: Climate for collections conference, vol. 79. Munich: Doerner Institut; 2012. p. 4558.

33. Baggio P, Bonacina C, Romagnoni P, Stevan AG. Microclimate analysis of the scrovegni chapel in padua - measurements and simulations. Stud Conserv. 2004:49(3):161-76.

34. Ascione F, Minichiello F. Microclimatic control in the museum environment: air diffusion performance. Int J Refrig. 2010;33(4):806-14.

35. Albero S, Giavarini C, Santarelli ML, Vodret A. CFD modeling for the conservation of the Gilded Vault Hall in the Domus Aurea. J Cult Herit. 2004;5(2):197-203.

36. Stazi F, Vegliò A, Di Perna C, Munafò P. Experimental comparison between 3 different traditional wall constructions and dynamic simulations to identify optimal thermal insulation strategies. Energy Build. 2013:60:429-41.

37. Steeman HJ, Van Belleghem M, Janssens A, De Paepe M. Coupled simulation of heat and moisture transport in air and porous materials for the assessment of moisture related damage. Build Environ. 2009:44(10):2176-84.

38. Pasquarella C, Balocco C, Pasquariello G, Petrone G, Saccani E, Manotti P, et al. A multidisciplinary approach to the study of cultural heritage environments: experience at the Palatina Library in Parma. Sci Total Environ. 2015;536:557-67.

39. Litti G, Audenaert A, Braet J. Natural ventilation as passive cooling strategy aimed at summer overheating reduction in heritage buildings: the case study of Vleeshuis Museum in Antwerp (Belgium). In: The European conference on sustainability, energy and the environment.

40. Balocco C, Petrone G, Maggi O, Pasquariello G, Albertini R, Pasquarella C. Indoor microclimatic study for cultural heritage protection and preventive conservation in the Palatina Library. J Cult Herit. 2016;22:956-67.

41. Grau-Bové J, Strlič M, Mazzei L. Applicability of a drift-flux model of aerosol deposition in a test tunnel and an indoor heritage environment. Build Environ. 2016;106:78-90.

42. Brandl D, Ruisinger DIU. Analysis of the thermal behavior of historical box type windows for renovation concepts with CFD. In: Sustainable building conference, Graz; 2013.

43. Kurabuchi T, Ogasawara T, Ochiai H, Lee S. A study on the indoor environment of the main building of the national museum of western art, in Japan, for the development of a retrofit scheme. Int J Vent. 2013;12(2):119-28.

44. D'Agostino D, Congedo PM, Cataldo R. Computational fluid dynamics (CFD) modeling of microclimate for salts crystallization control and artworks conservation. J Cult Herit. 2014;15(4):448-57.

45. Schellen H, van Schijndel A, Neilen D, van Aarle M. Damage to a monumental organ due to wood deformation caused by church heating. In: 2nd international conference on research in building physics, Leuven, Belgium; 2003.

46. Guimaraes AS, Delgado JMPQ, de Freitas VP. Mathematical analysis of the evaporative process of a new technological treatment of rising damp in historic buildings. Build Environ. 2010;45(11):2414-20. 
47. Caruso G, Mariotti M, de Santoli L. CFD analysis and risk management approach for the long-term prediction of marble erosion by particles impingement. CFD Lett. 2013;5(3):108-19.

48. Cortella G, Manzan M, Comini G. CFD simulation of refrigerated display cabinets. Int J Refrig. 2001;24(3):250-60.

49. Sun $Y, W u Y$, Wilson R, Lu S. Experimental measurement and numerical simulation of the thermal performance of a double glazing system with an interstitial Venetian blind. Build Environ. 2016;103:111-22.

50. Malekjani N, Jafari SM. Simulation of food drying processes by computational fluid dynamics (CFD); recent advances and approaches. Trends Food Sci Technol. 2018;78:206-23.

51. Tang L, Nikolopoulou M, Zhang N. Bioclimatic design of historic villages in central-western regions of China. Energy Build. 2014;70:271-8.

52. Fintikakis N, Gaitani N, Santamouris M, Assimakopoulos M, Assimakopoulos DN, Fintikaki M, et al. Bioclimatic design of open public spaces in the historic centre of Tirana, Albania. Sustain Cities Soc. 2011;1(1):54-62.

53. Clausen PA, Liu Z, Xu Y, Kofoed-Sørensen V, Little JC. Influence of air flow rate on emission of DEHP from vinyl flooring in the emission cell FLEC: measurements and CFD simulation. Atmos Environ. 2010;44(23):2760-6.

54. Aste N, Torre SD, Adhikari RS, Buzzetti M, Pero CD, Leonforte F, et al. Sustainable church heating: the Basilica di Collemaggio case-study. Energy Build. 2016;116:218-31.

55. Manual FU. Fluent Inc. Chapter. 2003;6:14-16

56. Liu HB, Lin N, Pan SS, Miao J, Norford LK. High sensitivity, miniature, full 2-D anemometer based on MEMS hot-film sensors. IEEE Sens J. 2013;13(5):1914-20.

57. Yasa E, Fidan G, Tosun M. Analysis of historic buildings in terms of their microclimatic and thermal comfort performances "example of Konya slender minaret Madrasah". J Arch Eng Technol. 2014;3(126):2.

58. Tablada de la Torre AE, Blocken B, Carmeliet J, De Troyer F, Verschure H. Airflow conditions and thermal comfort in naturally-ventilated courtyard buildings in a tropical-humid climate. In: 6th international conference on urban climate; 2006.
59. Srebric J, Vukovic V, He G, Yang X. CFD boundary conditions for contaminant dispersion, heat transfer and airflow simulations around human occupants in indoor environments. Build Environ. 2008;43(3):294-303.

60. Oh W, Kato S. The effect of airspeed and wind direction on human's thermal conditions and air distribution around the body. Build Environ. 2018;141:103-16.

61. Lipska B, Trzeciakiewicz Z, Ferdyn-Grygierek J, Popiołek Z. The improvement of thermal comfort and air quality in the historic assembly hall of a university. Indoor Built Environ. 2012;21(2):332-47.

62. Bonacina C, Cappellati F, Peron F, Romagioni P, Stevan AG. On the applicability of HVAC system for cultural heritage: the Wedding Chamber (Camera Picta) in Mantova (Italy). In: Historical and existing buildings: designing the retrofit. An overview from energy performances to indoor air quality; 2014.

63. Cao LN, Cao J, Lee S, Zhang Y, Tie X. Numerical simulation of the micro environment in the Han Yang Mausoleum museum. Aerosol Air Qual Res. 2012;12(4):544-52.

64. Ascione F, Bellia L, Capozzoli A. A coupled numerical approach on museum air conditioning: energy and fluid-dynamic analysis. Appl Energy. 2013:103:416-27.

65. Hussain S, Oosthuizen PH, Kalendar A. Evaluation of various turbulence models for the prediction of the airflow and temperature distributions in atria. Energy Build. 2012;48:18-28.

66. Nielsen PV. The selection of turbulence models for prediction of room airflow. Dept. of Building Technology and Structural Engineering; 1998.

67. Franke J, Hellsten A, Schlünzen H, Carissimo B. The COST 732 best practice guideline for CFD simulation of flows in the urban environment: a summary. Int J Environ Pollut. 2011;44(1-4):419-27.

68. Chen Q, Jelana S. A procedure for verification, validation, and reporting of indoor environment CFD analyses. HVAC\&R Res. 2002;8(2):201-16.

\section{Submit your manuscript to a SpringerOpen ${ }^{\odot}$ journal and benefit from:}

- Convenient online submission

- Rigorous peer review

- Open access: articles freely available online

- High visibility within the field

- Retaining the copyright to your article

Submit your next manuscript at springeropen.com 